\title{
Assessing Organizational Users' Intentions and Behavior to Al Integrated CRM Systems: a Meta-UTAUT Approach
}

\author{
Sheshadri Chatterjee ${ }^{1} \cdot$ Nripendra P. Rana $^{2}$ (D) Sangeeta Khorana $^{3} \cdot$ Patrick Mikalef $^{4} \cdot$ Anuj Sharma $^{5}$
}

Accepted: 1 August 2021

(C) The Author(s) 2021

\begin{abstract}
This paper tests the meta-analysis based unified theory of acceptance and use of technology (meta-UTAUT) model to predict the behavioral intentions of organizational users and their use behavior to artificial intelligence (AI) integrated customer relationship management (CRM) systems. Data was collected from 315 organizational users in India. The hypotheses draw on the theoretical underpinnings which have been statistically validated. Results show that CRM quality and satisfaction significantly influences an organization's employees attitudes and intentions to use AI integrated CRM systems. The compatibility of CRM systems has, however, a limited impact on employees attitudes. The findings, which are aligned with the extended UTAUT model, provide useful insights into organizations and decision-makers for designing AI integrated CRM systems.
\end{abstract}

Keywords AI-CRM $\cdot$ CRM Quality $\cdot$ CRM satisfaction $\cdot$ User behavior $\cdot$ Meta-UTAUT

\section{Introduction}

Customer Relationship Management (CRM) is considered an effective tool by organizations to identify their best customers. This tool helps to maximize the value by increasing customer satisfaction and retaining the clients (Kennedy, 2006; Sharma et al., 2019). CRM has been described as a systematic tool to achieve customers satisfaction and organizational performance (Coltman et al., 2011; Nguyen \& Mutum, 2012; Reinartz et al., 2004). The CRM ability of an organization is measured by its capability to accurately analyze customer related data (Keramati et al., 2010; Kumar \& Reinartz, 2006). However, analyzing the growing magnitude of customers data using manual techniques is difficult and has resulted in the need to use Information and Communication Technology
(ICT) and Artificial Intelligence (AI) application in CRM, also termed AI integrated CRM (Molinillo \& Japutra, 2017; Chatterjee et al., 2019). Business organizations are increasingly using $\mathrm{AI}$ integrated CRM system for accurate results which suggests that organizations intending to apply AI integrated CRM systems must motivate employees to use such systems (Chatterjee et al., 2021). This, however, requires an assessment of employees use behavior. To analyze the use behavior of employees to AI integrated CRM system, their attitudes and intentions must be aligned to support using the system because their intentions and attitudes predict use behavior (Chatterjee et al., 2020; Dwivedi et al., 2017; Gupta et al., 2019b). This suggests that the factors impacting the attitudes and intentions of users to $\mathrm{AI}$ integrated CRM systems need to be identified. This paper examines employees use behavior
Nripendra P. Rana

nrananp@gmail.com; nrana@qu.edu.qa

Sheshadri Chatterjee

sheshadri.academic@gmail.com

Sangeeta Khorana

skhorana@bournemouth.ac.uk

Patrick Mikalef

patrick.mikalef@ntnu.no

Anuj Sharma

f09anujs@iimidr.ac.in
Department of Computer Science \& Engineering, Indian Institute of Technology Kharagpur, Kharagpur, West Bengal 721302, India

2 College of Business and Economics, Qatar University, DohaP. O. Box 2713, Qatar

3 Bournemouth University Business School Bournemouth University, BH8 8EB Bournemouth, UK

4 Norwegian University of Science and Technology, NO-7491 Trondheim, Norway

5 Chandragupt Institute of Management Patna Mithapur Institutional Area, 800001 Patna, India 
and intentions to AI-integrated CRM system with the extended and modified UTAUT model. Extant literature highlights that the AI-CRM-KM system helps to technologically moderate the organizations knowledge management systems (Chatterjee et al., 2020). Studies also observe that the buyer-supplier relationship is impacted by the behavioral intentions of buyers and suppliers (Graca et al., 2015). There are no extant studies that explicitly investigate how employees behavior is likely to impact the adoption of AI integrated CRM system in an organization. Against this background, this study addresses the following objectives:

[1] To examine users behavior and intentions to AI integrated CRM system in organizations which is done with the extended UTAUT model.

[2] To investigate the impacts of CRM quality and satisfaction on employees attitudes and behavioral intentions to use AI integrated CRM system.

The remainder of the paper is arranged as follows. Section 2 reviews the literature. Section 3 introduces the theoretical background followed by formulation of hypotheses and development of a model in Section 4. The subsequent Section 5 presents the research methodology, Section 6 discusses the results implications and limitations. Section 7 concludes.

\section{Background Literature and Theoretical Background: a Meta-UTAUT Approach}

\subsection{Use of Al-integrated CRM System by Organizations}

Studies reveal that AI integrated CRM systems facilitate the computationally intensive analysis of large volume of customers' data at low cost (Chatterjee et al., 2019; Libai et al., 2020). The analysis of customers' data provides organizations effective inputs on how to strengthen the quality of customer relationships (Zablah et al., 2004; Dwivedi et al., 2019). Such data are huge in volume and AI ensures an accurate and swift analysis (Chatterjee et al., 2020; Verma \& Verma, 2013). Using AI, it is possible for organizations to make precise decisions by analyzing masses of customers' data effectively and efficiently (Dwivedi et al., 2019; Greenberg, 2010; Sharma et al., 2019). For AI to be employed, it is important that an organizations' employees responsible for analyzing customers data make diligent use of AI integrated CRM system. Such systems support organizations to accurately analyze the likes, habits, dislikes of the customers (Chatterjee et al., 2019; Sharma \& Sharma, 2019). However, the uptake of AI integrated CRM system in organizations is facilitated if compatible technology exists (Dwivedi et al., 2017; Venkatesh et al., 2003). A study examining the uptake of mobile learning by university students highlighted that satisfaction is an important predictor of behavioral intention for adopting information science and information technology (Kabra et al., 2017).

\subsection{Modified UTAUT Model}

Efficient implementation of any information system (IS) primarily depends on its acceptance by users (Davis, 1989). In recent times, in the domain of IS, psychology, and sociology, it has been observed that a plethora of theoretical models have been developed to explore and predict users' acceptance of IS (Dwivedi et al., 2017; Kabra et al., 2017; Sharma et al., 2018). Among these models, many researchers advocate the technology acceptance model (TAM) (Chauhan \& Jaiswal, 2016; Cimperman et al., 2016; Sumak \& Sorgo, 2016). Some scholars highlight the drawbacks of TAM (Sanchez-Prieto et al., 2016) as it provides insufficient insights into individuals' perspectives of a new system. TAM directly investigates the external variables like the perceived usefulness and perceived ease of use whilst neglecting the indicators and ignores the linkage between use and attitudes as well as use and intentions (Tsai et al., 2018). Further, there are additional challenges that support the choice of other contemporary models (Chao, 2019).

In the quest of an effective technology acceptance model and to address the existing drawbacks of other models, Venkatesh et al. (2003) attempted to integrate the core ingredients from eight prominent theories and models to predict and explain the new technology acceptance as well as usage and proposed a model called unified theory of acceptance and use of technology (UTAUT). It is worth mentioning that the UTAUT model includes the theory of reasoned action (TRA), information diffusion theory (IDT), theory of planned behavior (TPB), technology acceptance model (TAM), a combined model of TAM and TPB (C-TAM-TPB), motivational model (MM), model of personal computer utilisation (MPCU), and social cognitive theory (SCT) (Venkatesh et al., 2003).

The UTAUT model has been extensively used in different contexts, including field communication technology for predicting systems usage, supporting technology-embedded acceptance and usage-oriented decisions, (Khalilzadeh et al., 2017), home-health services (Cimperman et al., 2016), mobile-health (Hoque \& Sorwar, 2017), etc. The UTAUT model has effectively contributed to technology acceptance and usage. Hence, this paper considers the UTAUT model as a basis for appropriately evaluating the related antecedents in the use of AI integrated CRM system in an organization. However, many researchers opined that it is doubtful if this model can analyze the individuals' technology acceptance behavior (Dwivedi et al., 2017; Chao, 2019). The UTAUT model has also been criticized by scholars on different grounds (Bagozzi, 2007; van Raaij \& Schepers, 2006). For example, Li (2020) observed that, for gaining high $\mathrm{R}^{2}$, the UTAUT 
model considered four moderators which were impractical and not necessary, and it was observed that good predicting power would have been achieved using simple model by applying appropriate initial scoring procedure. Others stressed on the necessity to extend the UTAUT model by excluding some factors and including others according to the contextualization (Lin \& Anol, 2007; Wang et al., 2007; Wang \& Wang, 2010; Chao, 2019; Dwivedi et al., 2020). Table 1 presents the summary of external variables employed in meta-UTAUT model.

This paper argues that since organizations are likely to adopt AI integrated CRM system the question of society influencing the employees of organizations and voluntariness of the employees is redundant. Thus, this paper drops the construct social influence and the moderators used in UTAUT. The original UTAUT model did not consider direct linkages between facilitating conditions and behavioral intentions, but some studies suggest that using effort expectancy and the link between facilitating conditions and behavioral intentions provide a better explanation for use behavior (Dwivedi et al., 2020; Foon \& Fah, 2011). In the context of how to consider characteristics of individual behavior towards using a new technology, it is argued that attitude must be included to trigger intentions and use behavior (Carter \& Schaupp, 2008; Chong, 2013; Rana et al., 2016, 2017). In this study, compatibility is included as an exogenous variable. This is aligned with another work that includes compatibility as a factor in dealing with the UTAUT model (Karahanna et al., 2006). Our paper also employs attitude as a mediating variable (Koh et al., 2010; Alshare \& Lane, 2011). Moreover, this study also considers two exogeneous contextual variables -CRM quality and CRM satisfaction since these explain adoption and use behavior. The variables used for this analysis are in line with the observation that the UTAUT model can be extended with other contextual constructs, which explain individuals' acceptance and use behavior of individuals (Dwivedi et al., 2017).

\section{Proposed Conceptual Model and Hypotheses Development}

The proposed model provides evidence that the UTAUT model includes performance expectancy, effort expectancy, and facilitating conditions as exogenous variables. This paper considers compatibility, CRM quality, and CRM satisfaction as additional exogeneous variables, and attitude as mediating variables.

\subsection{Performance Expectancy}

Performance expectancy (PE) is defined as the level to which an individual believes that the system helps to improve job performance (Venkatesh et al., 2003). The concept is associated with the usefulness of a technology. An individual using a system thinks that by applying the system it will enhance the performance of the individual towards discharging his or her job. PE is conceptualized with the quality development of one's job and is concerned with the belief of the employees of organizations using AI integrated CRM system that the use of AI integrated CRM system would enhance performances (Chatterjee et al., 2019). Venkatesh et al. (2003) advocate that $\mathrm{PE}$ is the strongest factor of behavioral intention (BI) for adopting technology. Attitude plays a pivotal role and is expected to be affected by PE. Attitude is conceptualized as an individual's characteristics affecting the behavior to adopt AI integrated CRM system, (Chong, 2013; Rana et al., 2016, 2017). These discussions provide the basis for the following hypotheses:

H1a: Performance expectancy has a positive impact on employees' attitude to use AI integrated CRM system in organizations.

H1b: Performance expectancy has a positive impact on employees' behavioral intention to use AI integrated CRM system in organizations.
Table 1 Summary of external variables used in meta-UTAUT model in last five years (20162020)

\begin{tabular}{ll}
\hline Source & External variables used \\
\hline Tarhini et al. (2016) & Perceived Credibility, Task Technology Fit \\
Kuciapski (2017) & Relative usability, User autonomy \\
Thongsri et al. (2018) & Cognitive Need, Affective Need, Social Need \\
Mansoori et al. (2018) & Trust in government, Trust in Internet, Education \\
Naranjo-Zolotov et al. (2019) & Competence, Meaning, Impact, Self-determination, Empowerment \\
Gupta et al. (2019a) & Perceived Credibility \\
Donmez-Turan (2019) & User Resistance, User Anxiety, Adoption Readiness, Attitude toward using \\
Gunasinghe et al. (2019) & Personal Innovativeness, Habit, Motivation \\
Sobti (2019) & Perceived Risk, Perceived Cost, Demonetization effect, Educational \\
Rahi et al. (2019) & Qualification \\
\hline
\end{tabular}




\subsection{Effort Expectancy}

Effort expectancy (EE) is a strong predictor of acceptance of technology. It is defined as the degree of ease linked with the use of the system (Venkatesh et al., 2003). Studies conceptualized that EE comprises of antecedents, which include complexity and the ease of use (Cimperman et al., 2016). In this study, EE represents employees' beliefs concerning to ease of use of AI integrated CRM system in an organization. The UTAUT model has considered that EE prompts to behavioral intention (BI) that has been supplemented in other studies (Casey \& Wilson-Evered, 2012; Kijsanayotin et al., 2009). The concept of EE is identical with the construct ease of use as envisaged in diffusion of innovation (DoI) theory. The ease of use is conceptualized as a degree to which the use of AI integrated CRM system in an organization is perceived to be simple or difficult (Jeng \& Tzeng, 2012). Moreover, the use of technology by users depends on their individual behavioral characteristics (Chong, 2013). In line with other empirical studies, EE influences individuals' attitude to use a technology (Dwivedi et al., 2017). These result in the formulation of the following hypotheses:

H2a: Effort expectancy positively impacts the attitude of individuals to use AI integrated CRM system in organizations.

$\mathrm{H} 2 \mathrm{~b}$ : Effort expectancy positively impacts the behavioral intention of individuals to use AI integrated CRM system in organizations.

\subsection{Facilitating Conditions}

Facilitating conditions (FC) are interpreted as the degree to which a person perceives that the technical infrastructure exists to support the use of new technology, like AI integrated CRM systems (Chatterjee et al., 2019; Venkatesh et al., 2003). Earlier studies found that the acceptance of a specific technology is determined by FC, which considerably impacts the adoption of innovative technology on usage behavior (Lee et al., 2013). It is easier for the employees to use AI integrated CRM system if the existing technological infrastructure is user-friendly and supports usage of the system by its employees (Venkatesh et al., 2003). Thus, employees' attitude of using AI integrated CRM system is positively inclined to use the system with appropriate technological infrastructure (Chong, 2013). The above discussions formulate the following hypotheses:

H3a: Facilitating conditions positively impact attitude of individuals to use AI integrated CRM system.

$\mathrm{H} 3 \mathrm{~b}$ : Facilitating conditions positively impact use behavior of AI-CRM in organization.
H3c: Facilitating conditions positively impact behavioral intentions with regard to use of AI integrated CRM system in organizations.

\subsection{Compatibility}

Compatibility (COM) is interpreted as the extent to which new technology usage befits an organization (Rogers, 1962). This is assessed by the degree of congruence between modern technology and the various stages for the utilization of technology (Karahanna et al., 2006). The employees who perceive that AI integrated CRM technology is highly compatible when compared with their earlier experience can handle the AI integrated CRM system more effectively (Karahanna et al., 2006). The sense of compatibility of employees attempting to use a new technology is perceived to influence their attitude to use that technology. This is like the attitude of using online and mobile banking in China (Laforet \& Li, 2005; Khare, 2010). Compatibility helps a user to do things with ease if earlier experience supports the user (Wang et al., 2017). Further, the sense of compatibility is perceived to affect the use behavior through users' attitude (Kim et al., 2009; Rana et al., 2017). The above discussions will result in formulating the following hypotheses:

H4a: Compatibility positively impacts individuals' attitude of the employees of organizations to use AI integrated CRM system.

H4b: Compatibility positively impacts behavioral intention of the employees of organizations to use AI integrated CRM system.

\subsection{CRM Quality}

An organization must develop high quality customer relationship that delivers customer value beyond core products (Dalla Pozza et al., 2018; Zineldin, 2006). Studies suggest that the CRM quality is considered fundamental to maintaining high quality service (Chen \& Hu, 2013). High quality CRM abilities include attracting, maintaining, and developing efficient and successful relationship with customers over time (Berry, 1995). It also includes targeting customers with appropriate services and products at the right time (Swift, 2001). Quality CRM also includes developing customers' loyalty and profitability (Gronroos, 2007). The emergence of AI and its integration with the existing CRM system is expected to upgrade CRM quality (Chatterjee et al., 2019). AI is expected to support CRM activities to automate mundane and repetitive tasks (Dwivedi et al., 2019). AI-CRM would help updating data inputs and retrieval, updating sales forecast, and automating the process of accurate decision making (Chatterjee et al., 
2020). Thus, salespersons will be able to automatically target appropriate customers for developing business relationships. AI integrated CRM system could enhance the CRM quality by assessing the customers' appropriate habits history that would enable organizations to accurately customize and prioritize target customers (Chatterjee et al., 2019). The AI integrated CRM system is expected to enhance CRM quality that would impact employees' attitude and their intention to use AI integrated CRM system in organizations. These discussions lead to the formulation of the following hypotheses:

H5a: The integration of AI with CRM will improve CRM quality which in turn will positively impact employees' attitude to use AI integrated CRM system.

H5b: Integration of AI with CRM will improve CRM quality which in turn will positively impact employees' behavioral intention to use AI integrated CRM system.

\subsection{CRM Satisfaction (CRS)}

The concept of CRM is founded on the premise that developing a close relationship with the customers is perceived to be the best way to retain potential customers. CRM is conceptualized as a specific process to manage the complete relationship successfully between the organization and potential customers with interactive processes (Gronroos, 2007). The ability of CRM activities has been enhanced by integrating AI with CRM. AI integrated CRM system automatically gathers accurate insights from customers' data that help organizations to focus on appropriately developing the target profile (Libai et al., 2020). AI integrated CRM system may help organizations to retain more loyal customers as an organizations' future assets by facilitating cognitive engagement with customers (Youn \& Jin, 2021). AI integrated CRM system is expected to articulate an accurate roadmap to the organizations that would help and guide the sales team of the organizations to derive better results in any type of eventuality (Chatterjee et al., 2019). The integration of AI with CRM is expected to automate the customers' responses which would help the organizations to understand the customers' demographics as well as web behavior (Chatterjee et al., 2020). These are expected to enhance the employees' CRM satisfaction level and align individuals' attitude and behavioral intentions to use AI integrated CRM system in their organizations. These support us in generating the following hypotheses:

H6a: The integration of AI with CRM will enhance the CRM Satisfaction of employees that will positively impact the individuals' attitude of the employees to use AI integrated CRM system.

H6b: The integration of AI with CRM will enhance the CRM satisfaction of employees that will positively impact the behavioral intention of the employees to use AI integrated CRM system.

\subsection{Attitude}

Attitude (ATT) is a psychological antecedent, which is an emotional ability to characterize a person (Wood, 2000). It is a pre-disposed state of mind covering a value and is usually precipitated through a responsive expression of a person, place, and object (Dixon et al., 2015). This trait impacts one's actions and intentions. Attitudes are related with customers' individual behavior and attitude-behavior relationship (Lynn et al., 2012; Elizabeth et al., 2014). Ajzen (1991) observed that an attitude is conceptualized as a special feeling to perform a certain behavior in a positive or in a negative way. An attitude has a strong relationship with the users' intention to use a new technology, like AI integrated CRM system along with use behavior (Teo et al., 2008; Teo, 2009; Sadaf et al., 2012). Judged from this standpoint, the following hypotheses are derived:

H7: The employees' attitude in the organization has a positive impact on behavioral intention to use AI integrated CRM system.

H8: The employees' attitude in the organization has a positive impact on the use behavior of AI-CRM in organizations.

\subsection{Behavioral Intention}

Venkatesh et al. (2003) established that behavioral intention is a perfect predictor of use behavior. To perform a specific action, behavioral intention plays a formative role (Ajzen, 1991). Several studies observe that behavioral intentions of individuals to use an innovative technology prompt the use behavior to adopt that technology (Ajjan \& Hartshorne, 2008; Hartshorne \& Ajjan, 2009). Behavioral intention is conceptualized as an indication of readiness of an individual for performing a specific behavior and is perceived as an immediate consequence towards behavioral action (Ajzen, 2002). If employees of the organizations exhibit behavioral intention to use a new technology like AI integrated CRM system, they will also exhibit their use behavior to deploy that system. This formulates the following hypothesis:

H9: Employees' behavioral intentions in the organization positively influences their use behavior of AI-CRM.

Based on the above discussions, the proposed model is illustrated in Fig. 1. 
Fig. 1 Conceptual Model (Adapted from Dwivedi et al., 2017)

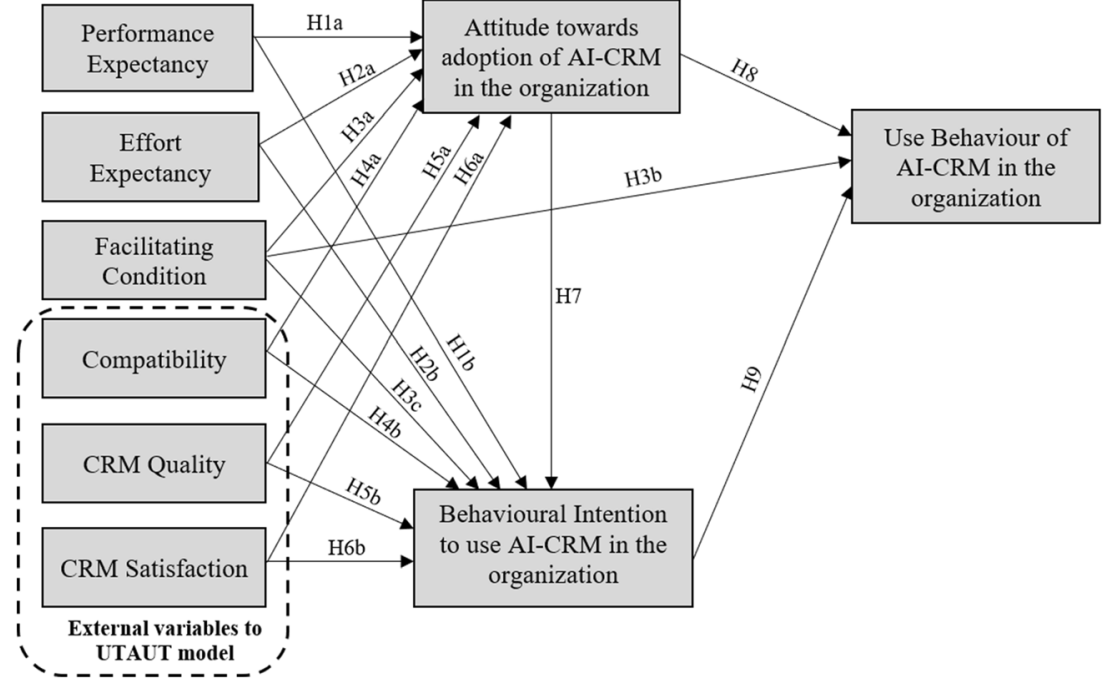

\section{Research Methodology}

The paper employs the Partial Least Square-Structural Equation Modelling (PLS-SEM) technique to examine the hypotheses and conceptual model. PLS-SEM approach supports analyzing an exploratory study (Hair et al., 2019) and a complex model with a comparatively small sample size is best analyzed with the PLS-SEM approach (Willaby et al., 2015). The PLS-SEM approach has proven to yield better results for studies that include marketing issues (Hair et al., 2012, 2016). PLS-SEM technique allows to analyze the data which are not normally distributed, this is not allowed in CB-SEM technique (Akter et al., 2017). The PLS-SEM approach involves the analysis of responses from the effective respondents against structured questionnaire and quantifies responses on a definite scale. In this study, a five-point Likert scale is used.

\subsection{Measurement Instrument}

From the prior related literature, a total of 32 questions were prepared in the form of statements for all the proposed constructs. The questions were framed in such a way that the respondents could understand the questions clearly. The questions were framed for realizing the attitude and notion of the employees from different organizations functioning with AI integrated CRM system (Mellahi \& Harris, 2016). To fine tune the questionnaire, four experts' opinion were sought who have knowledge in the domain of this study. To enhance the response rate, Dillman's approach (1991) was used which issues clear instructions to respondents on how to fill the response sheet with a cover letter (Baruch \& Holtom, 2008; Chidlow et al., 2015).

\subsection{Data Collection Strategy}

The respondents were selected from three cities in India. These were Delhi and National Capital Region (NCR), Bengaluru and Mumbai given high number of organizations that use AI integrated CRM system are located in these cities (Duupdates Report, 2020). The organizations that used AI integrated CRM systems were chosen at random in these cities. Top management's cooperation to promote employees' participation in the survey was solicited over telephone and email. Several rounds of conversations took place with the top executives of these firms highlighting the academic aim of the survey. Confidentiality and anonymity of respondents was assured in the survey. A total of 682 employees from 17 organizations participated in the survey. The respondents were from private organizations, multinational companies, public sector undertakings, and government organizations. The questionnaire was sent to the prospective 682 respondents with a request to respond within two months (i.e., during the months of January and February 2020). During the intervening period, they were requested through follow-up telephone and emails to expedite replies. Eventually, 367 responses were received within the allocated time, with a response rate of $53.8 \%$. For ensuring potential non-response bias, procedures suggested by Armstrong and Overtone (1977) were undertaken. Independent sample t-test and Chi square test were performed considering the first and last 110 respondents. No appreciable deviation of results was noted for these two groups $(\mathrm{p}<0.05)$ confirming that the responses are free from nonresponse bias. On scrutiny of the 367 responses, it was found that 52 responses were incomplete. A careful assessment revealed that 52 responses were incomplete because some of the respondents put tick marks in more than one option against a question or some of the respondents kept the response sheet totally unfilled. PLS-SEM analysis with the help of Smart PLS 3.2.4 
was conducted considering 315 usable responses against 32 survey questions. In terms of Deb and David (2014), we know that the ratio of number of items and number of participants should lie between 1:4 to 1:10. The questionnaire used in this study consisted of 32 items. Hence, as per Deb and David (2014), it is better if the number of usable respondents lies between 128 and 320. In this study, the final number of usable respondents is 315 which is within the permissible range. The demographic statistics of 315 respondents are presented in Table 2 .

\section{Results}

Data collected from 315 usable responses as per the five-point Likert scale was analyzed by the PLS-SEM approach. In the 5-point Likert scale, the responses are quantified as follows. Strongly Disagree has been marked as ' 1 ' to Strongly Agree has been marked as ' 5 '.

\subsection{Assessment of Measurement Properties and Discriminant Validity Test}

The convergent validity of each item was measured by estimating their loading factor (LF). For verifying consistency, reliability, validity, and multicollinearity defect of each construct, Cronbach's alpha $(\alpha)$, composite reliability (CR), average variance extracted (AVE), and variance inflation factor (VIF) have been estimated. The results shown in Table 3 highlight that all the parameters are within the allowable range.

Further, it is noted that square roots of all the AVEs exceed the corresponding correlation coefficients suggesting that Fornell and Larcker criteria (Fornell \& Larcker, 1981) have been satisfied confirming discriminant validity (see Table 4 ).

The Heterotrait-Monotrait (HTMT) ratio correlation test complements and confirms Fornell and Larcker criteria
(Henseler et al., 2014). The results presented in Table 5 highlight that all the constructs possess values less than 0.85 , confirming discriminant validity (Voorhees et al., 2016).

\subsection{Common Method Variance (CMV)}

Since the study is based on self-reported data, it is necessary to analyze the CMV. To reduce bias in the feedback, respondents were assured of confidentiality and anonymity which meant that they would provide unbiased response (Chang et al., 2010). The Single Factor Test (SFT) by Harman has been conducted which shows that the first factor resulted in 37.6 $\%$ variance and the value was less than the highest recommended value of $50 \%$ (Podsakoff et al., 2003), thus confirming CMV. To complement CMV, Marker-Variable Test has been conducted. The result revealed that correlation difference of original CMV and adjusted CMV concerning to all the relevant constructs was less than 0.06 (Lindell \& Whitney, 2001). From the knowledge of both the tests, it can be concluded that the data is unbiased and there is no chance of distorting the predictions.

\subsection{Assessment of Structural Equation Modelling (SEM)}

The model has been verified to ascertain the predictive relevance by the blindfolding process through consideration of bias correlated and accelerated bootstrapping procedure with 6000 resamples. The omission separation was considered as 5 to obtain cross-validated redundancy concerning to the exogeneous factors (Lew et al., 2016). The Stone-Geisser Q ${ }^{2}$ (Stone, 1974; Geisser, 1975) yielded value to the tune of 0.69 confirming that the model possesses predictive relevance.

To assess the model fit, the recommendation of Henseler et al. (2014) was followed and the Standard Root Mean
Table 2 Demographic statistics $(\mathrm{N}=315)$

\begin{tabular}{llll}
\hline Nature of the organizations & Hierarchy of the respondents & No. of respondents & Percentage (\%) \\
\hline Private limited organization & Senior Manager & 16 & 11.3 \\
& Mid-level Manager & 46 & 32.6 \\
& Junior Manager & 79 & 56.1 \\
Multinational company (MNC) & Senior Manager & 17 & 19.8 \\
& Mid-level Manager & 25 & 29.1 \\
& Junior Manager & 44 & 51.1 \\
Public sector undertaking (PSU) & Senior Manager & 8 & 12.9 \\
& Mid-level Manager & 20 & 32.2 \\
& Junior Manager & 34 & 54.9 \\
\multirow{3}{*}{ Government organizations } & Senior Manager & 4 & 15.4 \\
& Mid-level Manager & 10 & 38.5 \\
& Junior Manager & 12 & 46.1 \\
\hline
\end{tabular}


Table 3 Psychometric properties

\begin{tabular}{|c|c|c|c|c|c|c|c|c|c|}
\hline Construct| Items & Mean & $\mathrm{SD}$ & $\mathrm{LF}$ & $\begin{array}{l}\mathrm{t}- \\
\text { value }\end{array}$ & AVE & $\alpha$ & $\mathrm{CR}$ & VIF & No. of Items \\
\hline $\mathrm{PE}$ & & & & & 0.81 & 0.89 & 0.86 & 4.7 & 3 \\
\hline PE1 & 3.2 & 1.4 & 0.90 & 19.77 & & & & & \\
\hline PE2 & 4.1 & 1.7 & 0.95 & 21.02 & & & & & \\
\hline PE3 & 3.6 & 1.5 & 0.85 & 26.08 & & & & & \\
\hline $\mathrm{EE}$ & & & & & 0.77 & 0.85 & 0.81 & 4.2 & 3 \\
\hline EE1 & 4.1 & 1.1 & 0.85 & 23.14 & & & & & \\
\hline EE2 & 3.8 & 1.6 & 0.90 & 22.61 & & & & & \\
\hline EE3 & 3.6 & 1.9 & 0.88 & 26.92 & & & & & \\
\hline $\mathrm{FC}$ & & & & & 0.85 & 0.93 & 0.91 & 3.9 & 3 \\
\hline $\mathrm{FC} 1$ & 3.1 & 1.7 & 0.89 & 24.01 & & & & & \\
\hline $\mathrm{FC} 2$ & 4.1 & 1.3 & 0.95 & 28.02 & & & & & \\
\hline FC3 & 3.5 & 1.5 & 0.92 & 31.41 & & & & & \\
\hline $\mathrm{COM}$ & & & & & 0.83 & 0.89 & 0.88 & 4.1 & 3 \\
\hline COM1 & 2.9 & 1.4 & 0.89 & 26.28 & & & & & \\
\hline COM2 & 3.6 & 1.2 & 0.96 & 32.11 & & & & & \\
\hline COM3 & 3.5 & 1.9 & 0.88 & 29.76 & & & & & \\
\hline CRQ & & & & & 0.84 & 0.89 & 0.87 & 3.5 & 4 \\
\hline CRQ1 & 3.2 & 1.6 & 0.85 & 31.74 & & & & & \\
\hline CRQ2 & 3.8 & 1.7 & 0.87 & 28.21 & & & & & \\
\hline CRQ3 & 4.1 & 1.2 & 0.98 & 29.79 & & & & & \\
\hline CRQ4 & 3.6 & 1.4 & 0.94 & 19.99 & & & & & \\
\hline CRS & & & & & 0.87 & 0.93 & 0.91 & 3.9 & 4 \\
\hline CRS1 & 3.5 & 1.3 & 0.95 & 28.42 & & & & & \\
\hline CRS2 & 3.1 & 1.6 & 0.95 & 26.21 & & & & & \\
\hline CRS3 & 4.1 & 1.2 & 0.90 & 27.23 & & & & & \\
\hline CRS4 & 2.9 & 1.7 & 0.92 & 25.11 & & & & & \\
\hline ATT & & & & & 0.80 & 0.87 & 0.84 & 4.6 & 4 \\
\hline ATT1 & 2.7 & 1.9 & 0.85 & 26.17 & & & & & \\
\hline ATT2 & 3.7 & 1.6 & 0.90 & 28.14 & & & & & \\
\hline ATT3 & 2.8 & 1.8 & 0.95 & 32.11 & & & & & \\
\hline ATT4 & 3.1 & 1.3 & 0.88 & 28.72 & & & & & \\
\hline BI & & & & & 0.81 & 0.85 & 0.83 & 4.8 & 4 \\
\hline BI1 & 2.9 & 1.2 & 0.86 & 29.17 & & & & & \\
\hline BI2 & 3.2 & 1.4 & 0.88 & 34.16 & & & & & \\
\hline $\mathrm{BI} 3$ & 3.4 & 1.6 & 0.90 & 28.07 & & & & & \\
\hline BI4 & 3.3 & 1.7 & 0.95 & 19.97 & & & & & \\
\hline UBA & & & & & 0.82 & 0.89 & 0.86 & 3.9 & 4 \\
\hline UBA1 & 2.7 & 1.4 & 0.89 & 28.11 & & & & & \\
\hline UBA2 & 2.9 & 1.6 & 0.87 & 26.07 & & & & & \\
\hline UBA3 & 3.8 & 1.8 & 0.94 & 25.43 & & & & & \\
\hline UBA4 & 3.1 & 1.9 & 0.91 & 19.71 & & & & & \\
\hline
\end{tabular}

Square Residual (SRMR) has been considered as an index. The result revealed that the values of SRMR are 0.062 with PLS and 0.034 with PLSc. Both are less than the permissible highest value of SRMR, which is 0.08 (Hu \& Bentler, 1998).
This process could estimate the path coefficients, probability values ( $\mathrm{p}$-values) and coefficient of determinants $\left(\mathrm{R}^{2}\right)$. With all these results, the model after validation is shown in Fig. 2. 
Table 4 Discriminant validity test (Fornell \& Larcker criteria)

\begin{tabular}{|c|c|c|c|c|c|c|c|c|c|c|}
\hline Construct & $\mathrm{PE}$ & $\mathrm{EE}$ & $\mathrm{FC}$ & $\mathrm{COM}$ & CRQ & CRS & ATT & BI & UBA & AVE \\
\hline $\mathrm{PE}$ & 0.90 & & & & & & & & & 0.81 \\
\hline $\mathrm{EE}$ & 0.24 & 0.88 & & & & & & & & 0.77 \\
\hline $\mathrm{FC}$ & 0.27 & $0.26 * *$ & 0.92 & & & & & & & 0.85 \\
\hline $\mathrm{COM}$ & 0.19 & 0.21 & 0.17 & 0.91 & & & & & & 0.83 \\
\hline CRQ & 0.17 & 0.32 & 0.19 & 0.21 & 0.92 & & & & & 0.84 \\
\hline CRS & 0.18 & 0.17 & $0.31 * * *$ & 0.17 & $0.26 * *$ & 0.93 & & & & 0.87 \\
\hline ATT & $0.31 *$ & 0.19 & 0.21 & 0.19 & 0.29 & 0.21 & 0.89 & & & 0.80 \\
\hline BI & 0.24 & 0.22 & 0.24 & $0.24 *$ & $0.17 *$ & $0.32 *$ & 0.26 & 0.90 & & 0.81 \\
\hline UBA & $0.23 * *$ & $0.24 *$ & $0.23 *$ & 0.19 & $0.19 * * *$ & 0.16 & $0.29 *$ & 0.22 & 0.91 & 0.82 \\
\hline
\end{tabular}

Note: $* \mathrm{p}<0.05 ; * * \mathrm{p}<0.01 ; * * * \mathrm{p}<0.001$

The path coefficients, $\mathrm{p}$-values, and $\mathrm{R}^{2}$ are shown in Table 6.

\section{Discussion}

All the 16 hypotheses formulated for this study were supported after validation, except $\mathrm{H} 4 \mathrm{~b}(\mathrm{COM} \rightarrow \mathrm{BI})$. $\mathrm{PE}$ and $\mathrm{EE}$ which are found to impact BI since the path coefficients are significant and are 0.19 and 0.17 , respectively. This is in consonance with UTAUT model (Venkatesh et al., 2003). Besides, the impacts of FC on UBA have been validated with path coefficient as $0.26(\mathrm{H} 3 \mathrm{~b})$. This has been supported by the UTAUT model. Studies reveal that FC impacts BI (H3c) and this linkage has been validated with path coefficient 0.14 . This is also supported by other studies (Foon \& Fah, 2011) especially on Kuala Lumpur's usage of internet banking. The study emphasized the necessity of inclusion of $\mathrm{BI}$ as a mediating variable. Besides, the linkage $\mathrm{FC} \rightarrow \mathrm{BI}(\mathrm{H} 3 \mathrm{c})$ received support from another study of Yeow and Loo (2009) where it was observed

Table 5 Discriminant validity test (HTMT criteria)

\begin{tabular}{llllllllll}
\hline Construct & PE & EE & FC & COM & CRQ & CRS & ATT & BI & UBA \\
\hline PE & & & & & & & & \\
EE & 0.37 & & & & & & & & \\
FC & 0.52 & 0.26 & & & & & & & \\
COM & 0.46 & 0.27 & 0.47 & & & & & & \\
CRQ & 0.33 & 0.31 & 0.49 & 0.35 & & & & \\
CRS & 0.38 & 0.34 & 0.51 & 0.37 & 0.38 & & & \\
ATT & 0.42 & 0.47 & 0.62 & 0.47 & 0.31 & 0.41 & & \\
BI & 0.57 & 0.50 & 0.61 & 0.41 & 0.43 & 0.47 & 0.38 & \\
UBA & 0.31 & 0.56 & 0.32 & 0.44 & 0.52 & 0.44 & 0.63 & 0.34 \\
\hline
\end{tabular}

the need of use of $\mathrm{BI}$ as mediating variable while analyzing the use behavior of the users of ATM in Malaysia. Our study reveals that PE, EE, FC, COM, CRQ, and CRS impact ATT which correspond to H1a, H2a, H3a, H4a, H5a, and H6a, respectively. These have been validated statistically and the concerned path coefficients are $0.31,0.42,0.33,0.09,0.48$, and 0.36 respectively. Among the impacts, the influence of CRQ on ATT is the highest (path coefficient is 0.48 ) followed by effects of CRS on ATT (path coefficient is 0.36). It signifies that, the effects of CRM Quality and CRM Satisfaction on the attitude of the employees are maximum compared to other factors.

The role of attitude to explain technology acceptance has been employed by extending the concept of UTAUT (Venkatesh et al., 2003). Empirical studies confirm the findings (Yang \& Yoo, 2004) and emphasize the importance of considering attitude to explain technology acceptance while revising technology acceptance model. Attitude is also considered a vital antecedent for the usefulness of technology. For example, Kim et al. (2009) show that attitude plays a vital role in technology acceptance. The validated hypotheses H1a, H2a, H3a, H4a, H5a, and H6a that explain the attitude received strong support from the concepts of TRA, TPB, and DTPB which are considered as standard adoption models. Our study reveals that Attitude (ATT) impacts Behavioral Intention (BI) and Use-Behavior (H7 and $\mathrm{H} 8)$ as the path coefficients are 0.34 , and 0.39 respectively. The mediating role of the endogenous variable ATT considered in our study has received supports from other studies (Kim et al., 2010; Alshare \& Lane, 2011; Chen \& Lu, 2011). Kim et al. (2010) find that the role of attitude has been effectively considered while analyzing hotel employees' usage behavior. In the study of Alshare \& Lane (2011), results were obtained by considering the mediating role of attitude while predicting students' learning outcomes in ERP course. In the study by Chen and $\mathrm{Lu}$ (2011), successful results were obtained considering attitude as mediating variable while synthesizing e-coupon 
Fig. 2 Validated model

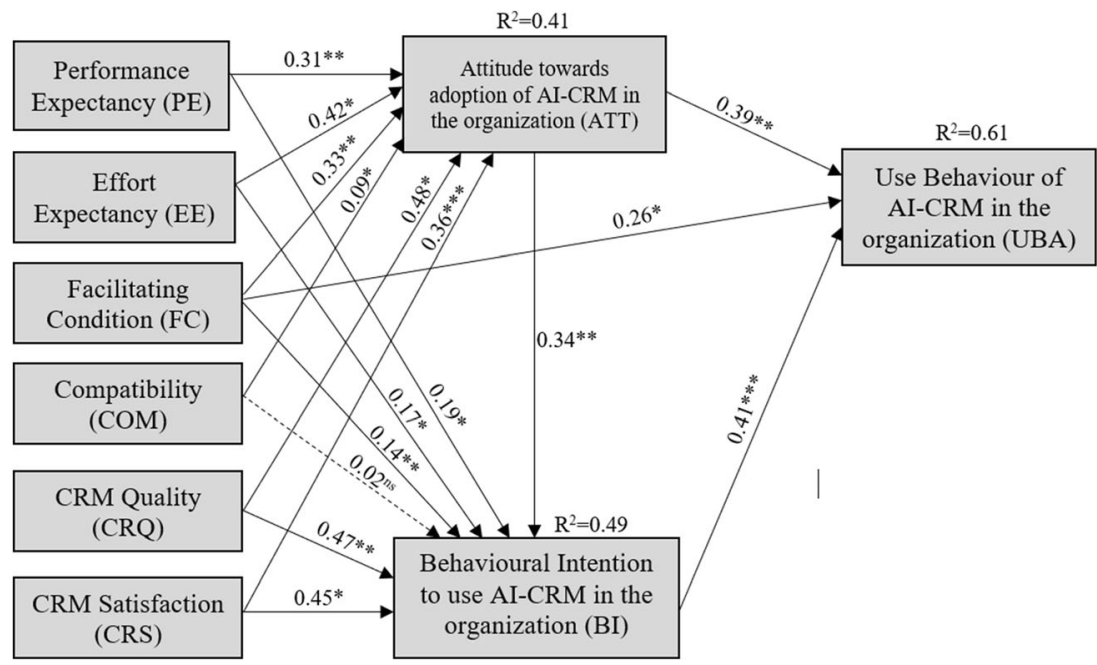

proneness in the context of analyzing extended TPB model. The linkage $\mathrm{COM} \rightarrow \mathrm{BI}$ (H4b) has not been supported statistically as the concerned path coefficient is 0.02 with level of non-significance, $\mathrm{p}>0.05$. This contradicts the work by Karahanna et al. (2006) examines reconceptualizing compatibility beliefs in technology acceptance, this is based on analysis of feedbacks on bank-related stakeholders in Northeast USA.

For our study, the feedback was taken from employees of organizations located in India. Our results vary from
Karahanna et al. (2006) findings, and this is explained by the difference in cultural dispositions between India and the USA (Gupta et al., 2018). It is pertinent to mention that CRQ and CRS have been considered as vital contextual predictors to impact both ATT and BI with high path coefficients. These have a vital role in predicting ATT and BI of the employees of organizations using AI integrated CRM system because employees of organizations are expected to be satisfied if they achieve better results by AI integration with CRM than just with CRM. For this, our study highlights that CRM quality is
Table 6 Values of path coefficients, $\mathrm{R}^{2}$, and $\mathrm{p}$-values

\begin{tabular}{|c|c|c|c|c|}
\hline Paths & Hypothesis & Path coefficient $\mid R^{2}$ value & $\begin{array}{l}\mathrm{p}- \\
\text { value }\end{array}$ & Hypothesis supported? \\
\hline Effects on ATT & & $\mathrm{R}^{2}=0.41$ & & \\
\hline By PE & H1a & 0.31 & $* *$ & Supported \\
\hline By EE & $\mathrm{H} 2 \mathrm{a}$ & 0.42 & $*$ & Supported \\
\hline By FC & $\mathrm{H} 3 \mathrm{a}$ & 0.33 & $* *$ & Supported \\
\hline By COM & $\mathrm{H} 4 \mathrm{a}$ & 0.09 & $*$ & Supported \\
\hline By CRQ & $\mathrm{H} 5 \mathrm{a}$ & 0.48 & $*$ & Supported \\
\hline By CRS & H6a & 0.36 & $* * *$ & Supported \\
\hline Effects on BI & & $\mathrm{R}^{2}=0.49$ & & \\
\hline By PE & $\mathrm{H} 1 \mathrm{~b}$ & 0.19 & $*$ & Supported \\
\hline By EE & $\mathrm{H} 2 \mathrm{~b}$ & 0.17 & * & Supported \\
\hline By FC & $\mathrm{H} 3 \mathrm{c}$ & 0.14 & $* *$ & Supported \\
\hline By COM & $\mathrm{H} 4 \mathrm{~b}$ & 0.02 & $\mathrm{~ns}$ & Not Supported \\
\hline By CRQ & $\mathrm{H} 5 \mathrm{~b}$ & 0.47 & $* *$ & Supported \\
\hline By CRS & $\mathrm{H} 6 \mathrm{~b}$ & 0.45 & $*$ & Supported \\
\hline By ATT & $\mathrm{H} 7$ & 0.34 & $* *$ & Supported \\
\hline Effects on UBA & & $\mathrm{R}^{2}=0.61$ & & \\
\hline By FC & $\mathrm{H} 3 \mathrm{~b}$ & 0.26 & $*$ & Supported \\
\hline By ATT & $\mathrm{H} 8$ & 0.39 & $* * *$ & Supported \\
\hline By BI & H9 & 0.41 & $* * *$ & Supported \\
\hline
\end{tabular}

Note: $\mathrm{p}$-value: $* * * \mathrm{p}<0.001, * * \mathrm{p}<0.01, * \mathrm{p}<0.05$, ns: non-Significant 
needed to be improved by properly integrating with AI, as confirmed by Libai et al. (2020). To improve the AI-CRM quality, data is to be curated to fit with AI applications and there must be effective AI algorithm. The AI integrated CRM system will have better quality if there is proper intersection of smarter data, unhindered access opportunity of vital customers' data and inexpensive but powerful cloud computing system (Chatterjee et al., 2019).

\subsection{Theoretical Contributions}

Our study provides substantial contributions to literature. The considerations of compatibility, CRM quality, and CRM satisfaction as exogeneous antecedents to analyze the use-behavior of the employees of organizations to use AI integrated CRM system have strengthened the model. Our study advances the understanding of behavioral intention and attitude of the employees of organizations to using AI integrated CRM system. This study also provides empirical evidence on the impacts of PE, EE, and FC that lead to impact use-related attitude and behavioral intention. In this way, our study provides an effective reference for the top executives of the organizations for deciding the direction for future development and successfully implement AI integrated CRM system in the organizations.

The study has derived evidence from prior research (Hoque \& Sorwar, 2017; Khalilzadeh et al., 2017) on how the three exogeneous variables of UTAUT model (PE, EE, and FC) could impact not only behavioral intentions but also the attitude of employees to use AI integrated CRM system. The inclusion of two contextual exogeneous antecedents - CRQ and CRS, which are perceived to appropriately motivate the employees in using AI integrated CRM system, has considerably strengthened the model of this study, and is yet another theoretical contribution.

Our study followed the inputs of UTAUT model but did not consider the societal factors and social influences as exogeneous factors. This has been done as organizations need to use AI integrated CRM system to improve their business and make its use mandatory for the employees of organizations. In line with this, the influence of society is considered redundant. Contextual factors are deemed to be vital to be considered as they trigger the focal phenomenon of a study directly or indirectly (Whetten, 2009). This is also another theoretical contribution of this study. Moreover, our study did not use the four moderators of UTAUT model because these do not fit with our study as discussed in the theoretical underpinning section of this paper. Kabra et al. (2017) conclude that satisfaction acts as a critical predictor of behavioral intentions. This study undertook mobile learning adoption by university students. This idea of Kabra et al. (2017) has been extended in our study to infer that CRM satisfaction could impact attitude and intention of the users to use AI integrated
CRM system in organizations. In line with Zineldin (2006), the loyalty and retention of customers depend on the quality of CRM. Our study has extended this concept with the additional factors such as CRM satisfaction and compatibility. Our study shows that these additional factors influence the users' attitude and behavioral intention towards the adoption of AI-CRM in an organization.

\subsection{Implications for Practice}

Our study reveals that attitude impacts intentions directly and the attitude of employees to use AI integrated CRM system in organizations. This implies that the managers of organizations have the duty to shape the attitude of the employees to use behavior to support AI integrated CRM system. Our study highlights that PE and EE (technological attributes) directly affect the intentions and attitudes of employees of an organization to using AI integrated CRM system. This implies that organizations employees emphasize the usefulness and easiness to use AI integrated CRM technology. Managers in organizations must keep software developers apprised on the consistency of employees' requirements that benefit existing knowledge so that the employees are inclined and compatible with using technology. The managers may also consider motivating the employees to use technology by communicating success stories of AI integrated CRM applications from other organizations (Dwivedi et al., 2015; Zuiderwijk et al., 2015). Our study confirms that FC and COM impact on attitudes and intentions of employees along with use-behavior for using AI integrated CRM system. This implies that the uptake by employees depends on the facilitating conditions and compatibility when using new systems. Our study highlights that COM impacts ATT less strongly (concerned path coefficient is 0.09) and has an insignificant impact on the intention of employees (concerned path coefficient is 0.02). This implies that managers must ensure appropriate employee training to ensure that employees are compatible using AI integrated CRM technology. This suggests that managers should provide appropriate infrastructural facilities to ensure that the employees are not constrained to using technology. Our study explains that CRQ and CRS significantly impacts employees ATT and BI (the values of path coefficients are considerably high) to using AI integrated CRM system in organizations. However, when an organization embarks on using AI integrated CRM system it faces challenges that include issues, such as the effectiveness of data, available expertise, infrastructural constraints, and other contextual problems (Schultz \& Pick, 2012; Chatterjee et al., 2019). Such challenges must be addressed by managers in organizations to improve CRM quality. If these are properly addressed, employees would be motivated to use AI integrated CRM system in their organizations. 


\subsection{Limitations and Future Research Directions}

This study suffers from limitations. Results are based on inputs from organizations in India and do not provide a global perspective. The study is cross-sectional, but the survey was conducted within a comparatively short span of time with a limited number of respondents $(\mathrm{N}=315)$. The employees' perception of PE, EE, FC, COM, CRQ, and CRS might change over time since employees' accumulate new knowledge with experience. Hence, future researchers may conduct a longitudinal study with a greater number of respondents for generalizing the results. The explanatory power of the model could also have been improved if other boundary conditions were considered, especially the concept of risk or trust of employees that might have impacted ATT and BI of the employees towards their use-behavior for AI-CRM usage in their organization. These issues are worthy and deserving of future research. This study should have analyzed a rival model to substantiate the effectiveness of the proposed model. But this is work for future researchers. In this study, the inputs have been taken from organizations in India. Thus, this study can be regarded as AI-CRM adoption in organizations in terms of Indian cultural aspects. Thus, Indian national culture could have an influence in the findings of this study, and this may be a limitation of this study. Future researchers can take a holistic attempt to understand the influence of national culture of different countries to the organizations and subsequently its influence on AI-CRM adoption by those organizations.

\section{Conclusions}

This study is a holistic attempt to develop a unique integrative model for India that explains the antecedents of an organization's employees to use AI integrated CRM system for promoting attitude and behavioral intentions to prompt use-behavior. The model was developed by extending the meta-UTAUT model. Our study has revealed that the proposed model possesses high internal reliability and consistency with better predictive power. Our study also shows that CRQ and CRS are vital exogenous variables that explain the use behavior of the employees mediating through ATT and BI. The determination of motivation to use a new technology, like AI integrated CRM system, is expected to boost instructional and pedagogical usage of modern technologies. In this manner, the results provide a tool for valuable decision making by decision makers in an organization.

Funding The open access funding for this research has been provided by the Qatar National Library.
Open Access This article is licensed under a Creative Commons Attribution 4.0 International License, which permits use, sharing, adaptation, distribution and reproduction in any medium or format, as long as you give appropriate credit to the original author(s) and the source, provide a link to the Creative Commons licence, and indicate if changes were made. The images or other third party material in this article are included in the article's Creative Commons licence, unless indicated otherwise in a credit line to the material. If material is not included in the article's Creative Commons licence and your intended use is not permitted by statutory regulation or exceeds the permitted use, you will need to obtain permission directly from the copyright holder. To view a copy of this licence, visit http://creativecommons.org/licenses/by/4.0/.

\section{References}

Ajjan, H., \& Hartshorne, R. (2008). Investigating faculty decisions to adopt Web 2.0 technologies: Theory and empirical tests. Internet and Higher Education, 11(2), 71-80

Ajzen, I. (1991). The theory of planned behavior. Organizational Behavioral and Human Decision Process, 50(2), 179-211

Ajzen, I. (2002). Perceived behavioral control, self-efficacy, locus of control, and the theory of planned behavior. Journal of Applied Social Psychology, 32(4), 665-683

Akter, S., Fosso Wamba, S., \& Dewan, S. (2017). Why PLS-SEM is suitable for complex modelling? An empirical illustration in big data analytics quality. Production Planning \& Control, 28(11/12), 10111021

Alshare, K. A., \& Lane, P. L. (2011). Predicting student-perceived learning outcomes and satisfaction in ERP courses: An empirical investigation. Communications of the Association for Information Systems, 28(1), 571-584

Armstrong, J. S., \& Overton, T. S. (1977). Estimating nonresponse bias in mail surveys. Journal of Marketing Research, 14(3), 396-402

Bagozzi, R. P. (2007). The legacy of the technology acceptance model and a proposal for a paradigm shift. Journal of the Association for Information Systems, 8, 244-254

Baruch, Y., \& Holtom, B. C. (2008). Survey response rate levels and trends in organizational research. Human Relations, 61(8), 1139 1116

Berry, L. L. (1995). Relationship marketing of services: growing interest, emerging perspectives. Journal of Academy of Marketing Science, 23(4), 236-245

Carter, L., \& Schaupp, L. C. (2008). Efficacy and acceptance in E-File adoption. Fourteenth Americas Conference on Information Systems, Toronto, ON, Canada

Casey, T., \& Wilson-Evered, E. (2012). Predicting uptake of technology innovations in online family dispute resolution services: an application and extension of the UTAUT. Computers in Human Behavior, 28(6), 2034-2045

Chang, S. J., Witteloostuijn, A. V., \& Eden, L. (2010). From the editors: Common method variance in international business research. Journal of International Business Studies, 41(2), 178-184

Chao, C-M. (2019). Factors determining the behavioral intention to use mobile learning: An application and extension of the UTAUT model. Frontiers in Psychology, 10, 1652-1664

Chatterjee, S., Ghosh, S. K., Chaudhuri, R., \& Nguyen, B. (2019). Are CRM systems ready for AI integration? A conceptual framework of organizational readiness for effective AI-CRM integration. The Bottom Line, 32(2), 144-157

Chatterjee, S., Ghosh, S. K., \& Chaudhuri, R. (2020). Knowledge management in improving business process: an interpretative framework for successful implementation of AI-CRM-KM system in 
organizations. Business Process Management Journal, In Press. https://doi.org/10.1108/BPMJ-05-2019-0183

Chatterjee, S., Chaudhuri, R., Vrontis, D., Thrassou, A., \& Ghosh, S. K. (2021). Adoption of artificial intelligence-integrated CRM systems in agile organizations in India. Technological Forecasting and Social Change, 168, 120783. https://doi.org/10.1016/j.techfore. 2021.120783

Chauhan, S., \& Jaiswal, M. (2016). Determinants of acceptance of ERP software training in business schools: empirical investigation using UTAUT model. International Journal of Management Education, 14(3), 248-262

Chen, P. T., \& Hu, H-H-S. (2013). The mediating role of relational benefit between service quality and customer loyalty in airline industry. Total Quality Management and Business Excellence, 24(9/10), 1084-1095

Chen, M. F., \& Lu, M. T. Y. (2011). Modeling e-coupon proneness as a mediator in the extended TPB model to predict consumers' usage intentions. Internet Research, 21(5), 508-526

Chidlow, A., Ghauri, P., Yeniyurt, S., \& Cavusgil, S. T. (2015). Establishing rigor in mail survey procedures in international business research. Journal of World Business, 50(1), 26-36

Chong, A. Y. L. (2013). Predicting m-commerce adoption determinants: A neural network approach. Expert Systems with Applications, 40, 523-530

Cimperman, M., Brencic, M. M., \& Trkman, P. (2016). Analyzing older users' home telehealth services acceptance behavior-applying an extended UTAUT model. International Journal of Medical Informatics, 90, 22-31

Coltman, T., Devinney, T. M., \& Midgley, D. F. (2011). Customer relationship management and firm performance. Journal of Information Technology, 26(3), 205-219. https://doi.org/10.1057/jit.2010.39

Dalla Pozza, I., Goetz, O., \& Sahut, J. M. (2018). Implementation effects in the relationship between CRM and its performance. Journal of Business Research, 89, 391-403. https://doi.org/10.1016/j.jbusres. 2018.02.004

Davis, F. D. (1989). Perceived usefulness, perceived ease of use, and user acceptance of information technology. MIS Quarterly, 13(3), 319339

Deb, M., \& David, E. L. (2014). An empirical examination of customer's adoption of m-Banking in India. Marketing Intelligence \& Planning, 32(4), 475-494

Dillman, D. A. (1991). The design and administration of mail surveys. Annual Review of Sociology, 17, 225-249

Dixon, G., Mckeever, B. W., Holton, A., \& Clarke, C. (2015). The power of a picture: Overcoming scientific misinformation by communicating weight-of-evidence information with visual exemplars: The power of a picture. Journal of Communication, 65(4), 639-659

Donmez-Turan, A. (2019). Does unified theory of acceptance and use of technology (UTAUT) reduce resistance and anxiety of individuals towards a new system? Kybernetes, 49(5), 1381-1405

Duupdates Report. (2020). Top MNC companies in India. https://www. duupdates.in/top-mnc-companies-in-india/. Accessed 12 July 2020

Dwivedi, Y. K., Wastell, D., Laumer, S., Henriksen, H. Z., Myers, M. D., Bunker, D., et al. (2015). Research on information systems failures and successes: Status update and future directions. Information Systems Frontiers, 17(1), 143-157

Dwivedi, Y. K., Rana, N. P., Jeyaraj, A., Clement, M., \& Williams, M. D. (2017). Re-examining the Unified Theory of Acceptance and Use of Technology (UTAUT): Towards a revised theoretical model. Information Systems Frontiers, 21, 719-734

Dwivedi, Y. K., Hughes, L., Ismagilova, E., Aarts, G., Coombs, C., Crick, T., \& Williams, M. D., .... (2019). Artificial Intelligence (AI): Multidisciplinary perspectives on emerging challenges, opportunities, and agenda for research, practice, and policy. International Journal of Information Management, 57, 101994
Dwivedi, Y. K., Rana, N. P., Tamilmani, K., \& Raman, R. (2020). A meta-analysis based modified unified theory of acceptance and use of technology (meta-UTAUT): A review of emerging literature. Current Opinion in Psychology, 36, 13-18

Elizabeth, A., Lynn, M., \& Khale, R. (2014). Belief Systems, Religion, and Behavioral Economics. Business Expert Press LLC. ISBN 9781-60649-704-3

Foon, Y. S., \& Fah, B. C. Y. (2011). Internet banking adoption in Kuala Lumpur: An application of UTAUT model. International Journal of Business and Management, 6(4), 161-167

Fornell, C., \& Larcker, D. F. (1981). Evaluating structural equation models with unobservable variables and measurement error. Journal of Marketing Research, 18(1), 39-50

Geisser, S. (1975). The predictive sample reuse method with applications. Journal of the American Statistical Association, 70(350), 320-328

Graca, S. S., Barry, J. M., \& Doney, P. M. (2015). Performance outcomes of behavioral attributes in buyer supplier relationships. Journal of Business and Industrial Marketing, 30(7), 805-816

Greenberg, P. (2010). The impact of CRM 2.0 on customer insight Journal of Business \& Industrial Marketing, 25(6), 410-419

Gronroos, C. (2007). Service management and marketing: Customer management in service competition. Wiley

Gunasinghe, A., Hamid, J. A., Khatibi, A., \& Azam, S. M. F. (2019). The adequacy of UTAUT-3 in interpreting academician's adoption to eLearning in higher education environments. Interactive Technology and Smart Education, 17(1), 86-106

Gupta, M., Uz, I., Esmaeilzadeh, P., Noboa, F., Mahrous, A. A., Kim, E., \& Azam, A. (2018). Do cultural norms affect social network behavior inappropriateness? A global study. Journal of Business Research, 85, 10-22

Gupta, K. P., Manrai, R., \& Goel, U. (2019a). Factors influencing adoption of payments banks by Indian customers: Extending UTAUT with perceived credibility. Journal of Asia Business Studies, 13(2), 173-195

Gupta, M., Esmaeilzadeh, P., Uz, I., \& Tennant, V. M. (2019b). The effects of national cultural values on individuals' intention to participate in peer-to-peer sharing economy. Journal of Business Research, 97, 20-29

Hair, J. F., Sarstedt, M., Ringle, C. M., \& Mena, J. A. (2012). An assessment of the use of partial least squares structural equation modeling in marketing research. Journal of the Academy of Marketing Science, 40, 414-433

Hair, J. F. Jr., Hult, G. T. M., Ringle, C., \& Sarstedt, M. (2016). A primer on partial least squares structural equation modeling (PLS-SEM) (2nd ed.). Sage Publications

Hair, J. F., Risher, J., Sarstedt, M., \& Ringle, C. M. (2019). When to use and how to report the results of PLS-SEM. European Business Review, 31(1), 2-24

Hartshorne, R., \& Ajjan, H. (2009). Examining student decisions to adopt Web 2.0 technologies: Theory and empirical tests. Journal of Computing in Higher Education, 21(3), 183-198

Henseler, J., Ringle, C. M., \& Sarstedt, M. (2014). A new criterion for assessing discriminant validity in variance-based structural equation modeling. Journal of the Academy of Marketing Science, 43(1), $115-135$

Hoque, R., \& Sorwar, G. (2017). Understanding factors influencing the adoption of mHealth by the elderly: an extension of the UTAUT model. International Journal of Medical Informatics, 101, 75-84

Hu, L., \& Bentler, P. M. (1998). Fit indices in covariance structure modeling: Sensitivity to under parameterized model misspecification. Psychological Methods, 3(4), 424-453

Jeng, D. J. F., \& Tzeng, D. H. (2012). Social influence on the use of clinical decision support systems: revisiting the unified theory of acceptance and use of technology by the fuzzy DEMATEL technique. Computers and Industrial Engineering, 62(3), 819-828 
Kabra, G., Ramesh, A., Akhtar, P., \& Dash, M. K. (2017). Understanding behavioural intention to use information technology: insights from humanitarian practitioners. Telematics \& Informatics, 34, 12501261

Karahanna, E., Agarwal, R., \& Corey, M. (2006). Reconceptualizing compatibility beliefs in technology acceptance research. MIS Quarterly, 30(4), 781-804

Kennedy, A. (2006). Electronic customer relationship management (eCRM): opportunities and challenges. Irish Marketing Review, 18(1/2), 58-69

Keramati, A., Mehrabi, H., \& Mojir, N. (2010). A process-oriented perspective on customer relationship management and organizational performance: An empirical investigation. Industrial Marketing Management, 39(7), 1170-1185. https://doi.org/10.1016/j. indmarman.2010.02.001

Khalilzadeh, J., Ozturk, A. B., \& Bilgihan, A. (2017). Security-related factors in extended UTAUT model for NFC based mobile payment in the restaurant industry. Computer in Human Behavior, 70, 460474

Khare, A. (2010). Online banking in India: An approach to establish CRM. Journal of Financial Services Marketing, 15(2), 176-188

Kijsanayotin, B., Pannarunothai, S., \& Speedie, S. M. (2009). Factors influencing health information technology adoption in Thailand's community health centers: applying the UTAUT model. International Journal of Medical Informatics, 78(6), 404-416

Kim, Y. J., Chun, J. U., \& Song, J. (2009). Investigating the role of attitude in technology acceptance from an attitude strength perspective. International Journal of Information Management, 29(1), 6777

Kim, T. T., Suh, Y. K., Lee, G., \& Choi, B. G. (2010). Modelling roles of task-technology fit and self-efficacy in hotel employees' usage behaviours of hotel information systems. International Journal of Tourism Research, 12(6), 709-725

Koh, C. E., Prybutok, V. R., Ryan, S. D., \& Wu, Y. A. (2010). A model for mandatory use of software technologies: An integrative approach by applying multiple levels of abstraction of informing science. The International Journal of an Emerging Trans discipline, 13, 177-203

Kuciapski, M. (2017). A model of mobile technologies acceptance for knowledge transfer by employees. Journal of Knowledge Management, 21(5), 1053-1076

Kumar, V., \& Reinartz, W. J. (2006). Customer relationship management: A databased approach. Hoboken: Wiley.

Laforet, S., \& Li, X. (2005). Consumers' attitudes towards online and mobile banking in China. International Journal of Bank Marketing, 23(5), 362-380

Lee, C. C., Lin, S. P., Yang, S. L., Tsou, M. Y., \& Chang, K. Y. (2013). Evaluating the influence of perceived organizational learning capability on user acceptance of information technology among operating room nurse staff. Acta Anesthesiologic Taiwanese, 51(1), 22-27

Lew, Y. K., Sinkovics, R. R., Yamin, M., \& Khan, Z. (2016). Transspecialization understanding in international technology alliances: The influence of cultural distance. Journal of International Business Studies, 47, 577-594

Li, J. (2020). Blockchain technology adoption: Examining the Fundamental Drivers. Proceedings of the 2nd International Conference on Management Science and Industrial Engineering, ACM Publication, April 2020, 253-260

Libai, B., Bart, Y., Gensler, S., Hofacker, C. F., Kaplan, A., Kötterheinrich, K., \& Kroll, E. B. (2020). Brave new world? On $\mathrm{AI}$ and the management of customer relationships. Journal of Interactive Marketing, 51, 44-56

Lin, C. P., \& Anol, B. (2007). Learning online social support: An investigation of network information technology. Cyber Psychology \& Behavior, 11(3), 268-272
Lindell, M. K., \& Whitney, D. J. (2001). Accounting for common method variance in cross-sectional research designs. Journal of Applied Psychology, 86(1), 114-121

Lynn, R., Kahle, P., \& Valette, F. (2012). Marketplace Lifestyles in an Age of Social Media. M.E. Sharpe, Inc. ISBN 978-0-7656-2561-8

Mansoori, K. A. A., Sarabdeen, J., \& Tchantchane, A. L. (2018). Investigating Emirati citizens' adoption of e-government services in Abu Dhabi using modified UTAUT model. Information Technology \& People, 31(2), 455-481

Mellahi, K., \& Harris, L. C. (2016). Response rates in business and management research: An overview of current practice and suggestions for future directions. British Journal of Management, 27(2), 426-437

Molinillo, S., \& Japutra, A. (2017). Organizational adoption of digital information and technology: a theoretical review. The Bottom Line, 30(1), 33-46

Naranjo-Zolotov, M., Oliveira, T., \& Casteleyn, S. (2019). Citizens' intention to use and recommend e-participation: Drawing upon UTAUT and citizen empowerment. Information Technology \& People, 32(2), 364-386

Nguyen, B., \& Mutum, D. S. (2012). A review of customer relationship management: successes, advances, pitfalls and futures. Business Process Management Journal, 18(3), 400-419

Podsakoff, P. M., MacKenzie, S. B., Lee, J. Y., \& Podsakoff, N. P. (2003). Common method biases in behavioral research: a critical review of the literature and recommended remedies. Journal of Applied Psychology, 88(5), 879-903

Rahi, S., Othman Mansour, M. M., Alghizzawi, M., \& Alnaser, F. M. (2019). Integration of UTAUT model in internet banking adoption context: The mediating role of performance expectancy and effort expectancy. Journal of Research in Interactive Marketing, 13(3), 411-435

Rana, N. P., Dwivedi, Y. K., Williams, M. D., \& Weerakkody, V. (2016). Adoption of online public grievance redressal system in India: Toward developing a unified view. Computers in Human Behavior, 59, 265-282

Rana, N. P., Dwivedi, Y. K., Lal, B., Williams, M. D., \& Clement, M. (2017). Citizens' adoption of an electronic government system: Towards a Unified View. Information Systems Frontiers, 19(3), 549-568

Reinartz, W., Krafft, M., \& Hoyer, W. D. (2004). The customer relationship management process: Its measurement and impact on performance. Journal of Marketing Research, 41(3), 293-305. https://doi. org/10.1509/jmkr.41.3.293.35991

Rogers, E. (1962). Diffusion of Innovations (1st ed.). Free Press

Sadaf, A., Newby, T. J., \& Ertmer, P. A. (2012). Exploring preservice teachers' beliefs about using Web 2.0 technologies in K-12 classroom. Computers \& Education, 59, 937-945

Sanchez-Prieto, J. C., Olmos-Migueláñez, S., \& García-Peñalvo, F. J. (2016). Informal tools in formal contexts: development of a model to assess the acceptance of mobile technologies among teachers. Computer in Human Behavior, 55, 519-528

Schultz, M., \& Pick (2012). From CM to CRM to CN2: A research agenda for the marketing communications transition. Advances in Advertising Research, 3, 421-432

Sharma, S. K., \& Sharma, M. (2019). Examining the role of trust and quality dimensions in the actual usage of mobile banking services: An empirical investigation. International Journal of Information Management, 44, 65-75

Sharma, S. K., Al-Badi, A., Rana, N. P., \& Al-Azizi, L. (2018). Mobile applications in government services (mG-App) from user's perspectives: A predictive modelling approach. Government Information Quarterly, 35(4), 557-568

Sharma, S. K., Sharma, H., \& Dwivedi, Y. K. (2019). A hybrid SEMneural network model for predicting determinants of mobile payment services. Information Systems Management, 36(3), 243-261 
Sobti, N. (2019). Impact of demonetization on diffusion of mobile payment service in India: Antecedents of behavioral intention and adoption using extended UTAUT model. Journal of Advances in Management Research, 16(4), 472-497

Stone, M. (1974). Cross validatory choice and assessment of statistical predictions. Journal of the Royal Statistical Society, 36(2), 111-147

Sumak, B., \& Šorgo, A. (2016). The acceptance and use of interactive whiteboards among teachers: differences in UTAUT determinants between pre and post-adopters. Computer in Human Behavior, 64, 602-620 Swift, R. S. (2001). Accelerating Customer Relationships: Using CRM and Relationship Technologies. Prentice Hall

Tarhini, A., El-Masri, M., Ali, M., \& Serrano, A. (2016). Extending the UTAUT model to understand the customers' acceptance and use of internet banking in Lebanon: A structural equation modeling approach. Information Technology \& People, 29(4), 830-849

Teo, T. (2009). Modeling technology acceptance in education: A study of preservice teachers. Computers and Education, 52(1), 302-312

Teo, T., Lee, C. B., \& Chai, C. S. (2008). Understanding preservice teachers' computer attitudes: Applying and extending the Technology Acceptance Model. Journal of Computer Assisted Learning, 24(2), 128-143

Thongsri, N., Shen, L., Bao, Y., \& Alharbi, I. M. (2018). Integrating UTAUT and UGT to explain behavioural intention to use M-learning: A developing country's perspective. Journal of Systems and Information Technology, 20(3), 278-297

Tsai, Y. Y., Chao, C. M., Lin, H. M., \& Cheng, B. W. (2018). Nursing staff intentions to continuously use a blended e-learning system from an integrative perspective. Quality and Quantity, 52(1), 2495-2513

van Raaij, E. M., \& Schepers, J. J. L. (2006). The acceptance and use of a virtual learning environment in China. Computers \& Education, 50(3), 838-852

Venkatesh, V., Morris, M. G., Davis, G. B., \& Davis, F. D. (2003). User acceptance of information technology: Toward a unified view. MIS Quarterly, 27(3), 425-478

Verma, D., \& Verma, D. S. (2013). Managing customer relationships through mobile CRM in organized retail outlets. International Journal of Engineering Trends and Technology, 4(5), 1696-1701

Voorhees, C. M., Brady, M. K., Calantone, R., \& Ramirez, E. (2016). Discriminant validity testing in marketing: an analysis, causes for concern, and proposed remedies. Journal of the Academy of Marketing Science, 44, 119-134

Wang, H. W., \& Wang, S. H. (2010). User acceptance of mobile Internet based on the Unified Theory of Acceptance and Use of Technology: Investigating the determinants and gender differences. Social Behavior \& Personality, 38(3), 415-426

Wang, Y. S., Wu, M. C., \& Wang, H. Y. (2007). Investigating the determinants and age and gender differences in the acceptance of mobile learning. British Journal of Educational Technology, 40(1), 92-118
Wang, M., Cho, S., \& Denton, T. (2017). The impact of personalization and compatibility with past experience on e-banking usage. International Journal of Bank Marketing, 35(1), 45-55

Whetten, D. A. (2009). An examination of the interface between context and theory applied to the study of Chinese organizations. Management and Organization Review, 5(1), 29-56

Willaby, H. W., Daniel, S. J., Costa, B. D., Burns, C. M., \& Richard, D. R. (2015). Testing complex models with small sample sizes: A historical overview and empirical demonstration of what partial least squares (PLS) can offer differential psychology. Personality and Individual Differences, 84, 73-78

Wood, W. (2000). Attitude change: Persuasion and social influence. Annual Review of Psychology, 51, 539-570

Yang, H. D., \& Yoo, Y. (2004). It's all about attitude: Revisiting the technology acceptance model. Decision Support Systems, 38(1), 19-31

Yeow, P. H., \& Loo, W. H. (2009). Acceptability of ATM and transit applications embedded in multipurpose smart identity card: An exploratory study in Malaysia. International Journal of Electronic Government Research, 5(2), 37-56

Youn, S., \& Jin, S. V. (2021). In A.I. we trust?” The effects of parasocial interaction and technopian versus luddite ideological views on chatbot-based customer relationship management in the emerging "feeling economy. Computers in Human Behavior, 119, 106721. https://doi.org/10.1016/j.chb.2021.106721

Zablah, A. R., Bellenger, D. N., \& Johnston, W. J. (2004). An evaluation of divergent perspectives on customer relationship management: Towards a common understanding of an emerging phenomenon. Industrial Marketing Management, 33(6), 475-489. https://doi. org/10.1016/j.indmarman.2004.01.006

Zineldin, M. (2006). The royalty of loyalty: CRM quality and retention. Journal of Consumer Marketing, 23(7), 430-437

Zuiderwijk, A., Janssen, M., \& Dwivedi, Y. K. (2015). Acceptance and use predictors of open data technologies: Drawing upon the unified theory of acceptance and use of technology. Government Information Quarterly, 32(4), 429-440

Publisher's Note Springer Nature remains neutral with regard to jurisdictional claims in published maps and institutional affiliations.

Anuj Sharma is a faculty member in the department of Information Systems at the Chandragupt Institute of Management Patna, India. He is a Fellow of the Indian Institute of Management Indore. His current research interests focus primarily on the development and use of information systems, scientometrics, data analytics, ecommerce digital marketing, and innovation. He has over 10 years of experience in management teaching, research, and consultancy at both Indian and international organizations.... 